\title{
Rheological Behavior of Gypsum, Plaster, and Hydroxyapatite Gel Blends
}

\author{
Mohamed Raii,* Francisco Javier Escudero Sanz, ${ }^{\dagger}$ and Ange Nzihou ${ }^{\ddagger}$ \\ Centre RAPSODEE, Mines Albi, CNRS, Université de Toulouse, Campus Jarlard, F-81013 Albi Cedex 09, France
}

\begin{abstract}
The rheological behavior of water-calcium sulfates and hydroxyapatite-calcium sulfates binary blends was considered in this study. These blends are to be used as permeable reactive barriers for groundwater remediation. The influence of gypsum and plaster on the rheological behavior of $\mathrm{Ca}-\mathrm{HA}_{\mathrm{Gel}}$ has been studied. The results show that all blends and formulations exhibit a shear-thinning effect and thixotropic behavior. The viscosity also depends on the level of concentration of the solid and the reactivity of the blends. The hydration of plaster causes cohesion and agglomeration between particles due to electrostatic forces, while the hydration of gypsum leads to dispersion due to repulsive forces between particles. The $\zeta$ potential was used in this study to understand the interaction between particles and its effect on the global behavior of the blends. The dissolution in water of sulfate ions containing calcium sulfate leads to a change in the surface charge of the blend. This allowed the dispersion or agglomeration of the mixtures to be predicted.
\end{abstract}

\section{INTRODUCTION}

Calcium phosphate is a well-known biomaterial frequently used in the medical domain and as an agricultural fertilizer. It can come from natural sources such as fish or cow bones or as a result of a synthesis process using calcium and phosphate compounds. Calcium phosphate has been investigated as a reactive material, especially in its thermodynamically stable structure with the stoichiometric ratio $\mathrm{Ca} / \mathrm{P}=1.67$ (hydroxyapatite, Ca-HA), to determine its usefulness in treating contaminated water or as a stabilizing agent for hazardous waste. $^{1-3}$ Many studies have also shown the capacity of Ca-HA to remediate soil and groundwater., ${ }^{4,5}$

Gypsum can have two origins: natural gypsum and synthetic gypsum. Natural gypsum, characterized by a high purity, is an anionic mineral with a $C_{2 h}^{6}$ space group. This gypsum is a rock resulting from the evaporation of water from saturated calcium sulfate and geological sedimentation. Synthetic gypsum is a byproduct of industrial activities. It is obtained from a reaction between sulfuric acid and phosphate rock to produce phosphoric acid $\left(\mathrm{H}_{3} \mathrm{PO}_{4}\right)$. The precipitate, usually named phosphogypsum (PG), is dihydrated calcium sulfate. This gypsum contains a significant amount of impurities and is considered to be a waste product. The environmental impact associated with PG storage and disposal, as reviewed by Tayibi et al., is negative on the surrounding land, water, and air. ${ }^{6}$ Valorization seems to be by far the best way to reuse this hazardous material. Industrial PG can be valorized as a material for soil stabilization. It can be added to Portland cement or to reactive materials such as fly ash to enhance the mechanical properties of the soil and to reduce the plasticity index, moisture, and water content. ${ }^{7}$ It can also be used as a hydraulic binder in the design of calcium sulfoaluminate cement. ${ }^{8}$ The calcium sulfates used in this work are industrial gypsum $\left(\mathrm{CaSO}_{4} \cdot 2 \mathrm{H}_{2} \mathrm{O}\right)$ and plaster $\left(\mathrm{CaSO}_{4} \cdot 0.5 \mathrm{H}_{2} \mathrm{O}\right)$. They are byproducts of phosphoric acid production and are washed to eliminate the residual fraction (phosphate, fluor, sodium, radionuclides, etc.).
There are three anhydrous or anhydrite forms produced by sintering of hemihydrates or gypsum: the compact form $\alpha$ $\mathrm{CaSO}_{4}$ or $\mathrm{CaSO}_{4}$-I, obtained at $1200{ }^{\circ} \mathrm{C}$ and characterized by a crystalline structure; the stable form $\beta-\mathrm{CaSO}_{4}$ or $\mathrm{CaSO}_{4}-\mathrm{II}$, obtained at $400{ }^{\circ} \mathrm{C}$, which is a natural insoluble anhydrite; the metastable form $\gamma$ - $\mathrm{CaSO}_{4}$ or $\mathrm{CaSO}_{4}$-III, obtained at low temperature between 130 and $200{ }^{\circ} \mathrm{C}$, which is a soluble anhydrite. ${ }^{9}$ The stability of gypsum is also influenced by the relative humidity $(\mathrm{RH})$. At $10-35 \% \mathrm{RH}$, the migration of water molecules takes place toward the crystals, while at $100 \% \mathrm{RH}$, the migration takes place in the opposite direction. ${ }^{10,11}$ The crystalline structure of the gypsum, characterized by a perfect cleavage orientation (010), results in the circulation of water, leading to dissolution on the surface $(010) \cdot{ }^{11,12}$ The blending of hemihydrates with water gives a rigid and compact solid body, due to the hydration process.

The main purpose of this work is to investigate the rheological behavior of water/gypsum, water/plaster, Ca-HA/ gypsum, and Ca-HA/plaster blends. This is a preliminary step in a project devoted to the formulation and characterization of a Ca-HA-based permeable reactive barrier. The evaluation of the rheological behavior of a mixture of gypsum and plaster on $\mathrm{Ca}-\mathrm{HA}_{\mathrm{Gel}}$ aims to better understand the development of the matrix microstructure and, consequently, to assess its workability.

\section{MATERIALS AND METHODS}

2.1. Calcium Sulfates. The gypsum $\left(\mathrm{G}, \mathrm{CaSO}_{4} \cdot 2 \mathrm{H}_{2} \mathrm{O}\right)$ and the plaster calcium sulfate $\left(\mathrm{P}_{\alpha}, \mathrm{CaSO}_{4} \cdot 0.5 \mathrm{H}_{2} \mathrm{O}\right.$, prepared by the wet method) used in this work are industrial byproducts of a phosphoric acid $\left(\mathrm{H}_{3} \mathrm{PO}_{4}\right)$ preparation from phosphate rock (PRAYON, Belgium). The plaster was used as received, and 
gypsum was sieved to under $1 \mathrm{~mm}$ and the larger fraction discarded.

2.2. Hydroxyapatite Gel $\left(\mathrm{Ca}-\mathrm{HA}_{\mathrm{Gel}}\right)$. $\mathrm{Ca}-\mathrm{HA}_{\mathrm{Gel}}$ was obtained by the reaction between calcite $\left(\mathrm{CaCO}_{3} ; 98 \%\right.$ pure, Fisher Scientific) and ammonium phosphate $\left(\mathrm{NH}_{4} \mathrm{H}_{2} \mathrm{PO}_{4}\right.$; 99.4\% pure, Fisher Scientific) at $25{ }^{\circ} \mathrm{C}$ with a molar ratio of $\mathrm{Ca} / \mathrm{P}=1.67$, and the amount of demineralized water is 3 times higher than that of calcite. The equation below describes the overall reaction pathway for the synthesis of Ca-HA. During the formation of $\mathrm{Ca}-\mathrm{HA}_{\mathrm{Gel}}$, bubbling corresponding to the release of $\mathrm{CO}_{2}$ gas was observed.

$$
\begin{aligned}
& 10 \mathrm{CaCO}_{3}+6 \mathrm{NH}_{4} \mathrm{H}_{2} \mathrm{PO}_{4}+2 \mathrm{H}_{2} \mathrm{O} \\
& \quad \rightarrow \mathrm{Ca}_{10}\left(\mathrm{PO}_{4}\right)_{6}(\mathrm{OH})_{2}+6 \mathrm{NH}_{4} \mathrm{OH}+2 \mathrm{H}_{2} \mathrm{O}+10 \mathrm{CO}_{2}
\end{aligned}
$$

At the beginning of the reaction, the $\mathrm{pH}$ value increased gradually from 6 to 8 and then stabilized after $12 \mathrm{~h}$ of synthesis. The stabilization of the $\mathrm{pH}$ revealed the formation of an ammonium hydroxide buffer and the consumption of calcium carbonate. Ca- $\mathrm{HA}_{\text {Powder }}$ was prepared by drying $\mathrm{Ca}-\mathrm{HA}_{\mathrm{Gel}}$ at $105{ }^{\circ} \mathrm{C}$ for $24 \mathrm{~h}$ to obtain a powder with monomodal particlesize distribution. The water content calculated after drying at $105{ }^{\circ} \mathrm{C}$ was $70 \%$. Ca- $\mathrm{HA}_{\mathrm{Gel}}$, destined to be used for chemical characterization, was filtered and rinsed with deionized water to dissolve any unreacted phosphate.

2.3. Physical and Chemical Characterization. Powder densities were measured using a helium pycnometer (AccuPyc $1330 \mathrm{~V} 2.04 \mathrm{~N})$. The specific surface areas of the materials (G, P, and Ca-HA) were determined on a Micromeritics Gemini 2360, by surface analysis using the Brunauer-Emmett-Teller method, and the measurements were performed by nitrogen absorption at liquid-nitrogen temperature followed by desorption (adsorption gas $\mathrm{N}_{2}$; heating temperature $150{ }^{\circ} \mathrm{C}$ ).

The particle-size distribution was determined by LASER granulometry using a Malvern Laser Master Sizer Hydro 2000 instrument (with ethanol as a dispersant shaken by ultrasound). The $\mathrm{pH}$ measurements were made after dispersion of $10 \mathrm{~g}$ of powder materials in $25 \mathrm{~mL}$ of deionized water and stirring for 1 $\mathrm{h}$ at room temperature, with the measurement being carried out after $2 \mathrm{~h}$. The particle charge was evaluated relative to the net charge on the particles' surfaces by evaluation of the $\mathrm{pH}$ point zero charge $\left(\mathrm{pH}_{\mathrm{PZC}}\right)$. This determination is based on the electrochemistry and involves the introduction of $50 \mathrm{~cm}^{3}$ of a $\mathrm{NaCl}(0.01 \mathrm{M})$ solution in closed vials and adjustment of the initial $\mathrm{pH}$ to values between 2 and 12 by the addition of $\mathrm{NaOH}$ or $\mathrm{HCl}(0.1 \mathrm{M})$. A mass of $0.15 \mathrm{~g}$ was added to the vials, and the final $\mathrm{pH}$ was measured and recorded after stirring for $48 \mathrm{~h}$ at room temperature. The $\mathrm{pH}_{\mathrm{PZC}}$ value corresponds to the intersection point of the titration curves obtained at one ionic strength for the suspension $\left(\mathrm{pH}_{\text {initial }}\right)$ and blank solution $\left(\mathrm{pH}_{\text {final }}\right)$.

$\mathrm{X}$-ray diffraction (XRD) analysis of the powders was performed on a Siemens D5000 XRD spectrometer using $\mathrm{Cu}$ $\mathrm{K}_{\alpha}(\lambda=1.540 \AA$ ) anticathode radiation (power $40 \mathrm{~mA}, 45 \mathrm{kV})$. The diffraction angle was set up from 10 to $80^{\circ} 2 \theta$ with a step count of $0.02^{\circ} 2 \theta$ and a counting time of $3 \mathrm{~s} / \mathrm{step}$. $\zeta$-Potential measurements were performed on a Zetasizer 3000 HSA (Malvern Instruments Ltd.).

The rheological measurements were performed using a Rheostress (HAAKE RS 150 rheometer). The rheological behavior and viscosity $\eta(\mathrm{Pa} \cdot \mathrm{s})$ were evaluated for shear rates ranging from 0 to $500 \mathrm{~s}^{-1}$ at constant temperature $\left(20 \pm 5^{\circ} \mathrm{C}\right)$. The sample was placed in a cylindrical vessel, and the strain was applied by a double-helical ribbon impeller. Samples were homogenized before the shear stress $\tau(\mathrm{Pa})$ and viscosity versus the applied shear rate $\dot{\gamma}\left(\mathrm{s}^{-1}\right)$ were measured. The dynamic trails applied on $\mathrm{Ca}-\mathrm{HA}_{\mathrm{Gel}}$ were performed with the same apparatus using an oscillation mode with a preselected constant shear stress of $50 \mathrm{~Pa}$ and a frequency ranging from 1 to $50 \mathrm{~Hz}$. The loss and storage moduli measurements were recorded for $300 \mathrm{~s}$ at room temperature.

2.4. Formulations. Rheological tests were carried out on pure $\mathrm{Ca}-\mathrm{HA}_{\mathrm{Gel}}$, on binary water/gypsum (W/G), and on water/plaster $(\mathrm{W} / \mathrm{P})$ blends. Binary blends were prepared by mixing the selected material with deionized water according to different mass ratios ranging from 0.4 to 1.4. The solid concentrations of binary blends $\left(\Gamma_{\mathrm{B} 1}\right)$ and the $\mathrm{W} / \mathrm{G}$ and $\mathrm{W} / \mathrm{P}$ mass ratios were calculated as follows:

$$
\Gamma_{\mathrm{B} 1}=\frac{V_{\mathrm{s}}}{V_{\mathrm{s}}+V_{\mathrm{w}}} ; \quad \frac{W}{G}=\frac{1-\Gamma_{\mathrm{B}}}{\rho_{\mathrm{G}} \Gamma_{\mathrm{B}}} ; \quad \frac{W}{P}=\frac{1-\Gamma_{\mathrm{B}}}{\rho_{\mathrm{P}} \Gamma_{\mathrm{B}}}
$$

where $V_{\mathrm{s}}$ is the volume of the solid phase, $V_{\mathrm{w}}$ is the volume of water, and $\rho_{\mathrm{G}}$ and $\rho_{\mathrm{P}}$ are the densities of gypsum and plaster, respectively. The $\mathrm{Ca}-\mathrm{HA}_{\mathrm{Gel}}$ content considered was from 0 to 50 wt \% Ca- $\mathrm{HA}_{\mathrm{Gel}}$. The rheological behaviors of water-free formulations $\left(\mathrm{Ca}-\mathrm{HA}_{\mathrm{Gel}} / \mathrm{G}\right.$ and $\left.\mathrm{Ca}-\mathrm{HA}_{\mathrm{Gel}} / \mathrm{P}\right)$ with mass ratios of 50/50, 40/60, and 30/70 were not considered because the pastes obtained were very thick and almost solids). The solid concentrations of binary blends $\left(\Gamma_{\mathrm{B} 2}\right)$ containing either gypsum or plaster (calcium sulfate powder) with $\mathrm{Ca}-\mathrm{HA}_{\mathrm{Gel}}$ were calculated as follows:

$$
\begin{gathered}
\Gamma_{\mathrm{B} 2}=\frac{V_{\mathrm{s}_{\mathrm{T}}}}{V_{\mathrm{s}_{\mathrm{T}}}+V_{\mathrm{w}_{\mathrm{T}}}} ; \quad V_{\mathrm{s}_{\mathrm{T}}}=V_{\mathrm{Ca}-\mathrm{HA}_{\mathrm{Powder}}}+V_{\mathrm{CS}_{\mathrm{Powder}}} ; \\
V_{\mathrm{w}_{\mathrm{T}}}=V_{\mathrm{Ca}-\mathrm{HA} \mathrm{W}_{\text {ater }}}
\end{gathered}
$$

where $V_{s_{\mathrm{T}}}$ is the total volume of the solid material equal to the sum of the Ca- $\mathrm{HA}_{\text {Powder }}$ volume $\left(V_{\mathrm{Ca}-\mathrm{HA}_{\mathrm{P}_{\text {owder }}}}\right)$ and the calcium sulfate powder volume $\left(V_{\mathrm{CS}_{\text {powder }}}\right)$ and $V_{\mathrm{w}_{\mathrm{T}}}$ is the total water equal to the Ca-HA water volume $\left(V_{\mathrm{Ca}-\mathrm{HA}_{\text {water }}}\right)$.

\section{RESULTS AND DISCUSSION}

3.1. Characteristics of the Materials. The results of the bulk density, specific surface area, and $\mathrm{pH}$ of the materials are given in Table 1. It can be seen that the bulk densities were

\begin{tabular}{|c|c|c|c|c|}
\hline & $\mathrm{G}_{\text {Powder }}$ & $\mathrm{P}_{\text {Powder }}$ & $\begin{array}{c}\mathrm{Ca}- \\
\mathrm{HA}_{\text {Powder }}\end{array}$ & $\begin{array}{c}\mathrm{Ca-} \\
\mathrm{HA}_{\mathrm{Gel}}\end{array}$ \\
\hline bulk density $\rho\left(\mathrm{g} \mathrm{cm}^{-3}\right)$ & 2.25 & 2.81 & 2.58 & 1.23 \\
\hline surface specific area $S_{\mathrm{SA}}\left(\mathrm{m}^{2} \mathrm{~g}^{-1}\right)$ & 26.27 & 72.81 & 138 & \\
\hline $\mathrm{pH}$ & 8.44 & 2.88 & 7.85 & 8.41 \\
\hline $\mathrm{pH}_{\mathrm{PZC}}$ & 7.50 & 3.30 & 8.11 & \\
\hline residual moisture at $105{ }^{\circ} \mathrm{C}(\%)$ & 20.00 & 5.00 & & 67 \\
\hline $\begin{array}{l}\text { loss upon ignition }\left(\text { at } 1000{ }^{\circ} \mathrm{C}\right) \\
(\%)\end{array}$ & 22.00 & 8.00 & 59.00 & \\
\hline \multicolumn{5}{|l|}{ granulometric fraction (\%) } \\
\hline sand & 79.6 & 48.9 & 43.4 & 9.0 \\
\hline silt & 18.7 & 49.0 & 51.7 & 88.0 \\
\hline clay & 1.7 & 1.7 & 4.9 & 3.0 \\
\hline
\end{tabular}
used to calculate the solid concentrations in the blends. The $\mathrm{pH}$ of plaster is acidic, which provides an indication of the presence of phosphoric acid. The specific surface area of plaster is 3

Table 1. Physical Characteristics of the Materials 


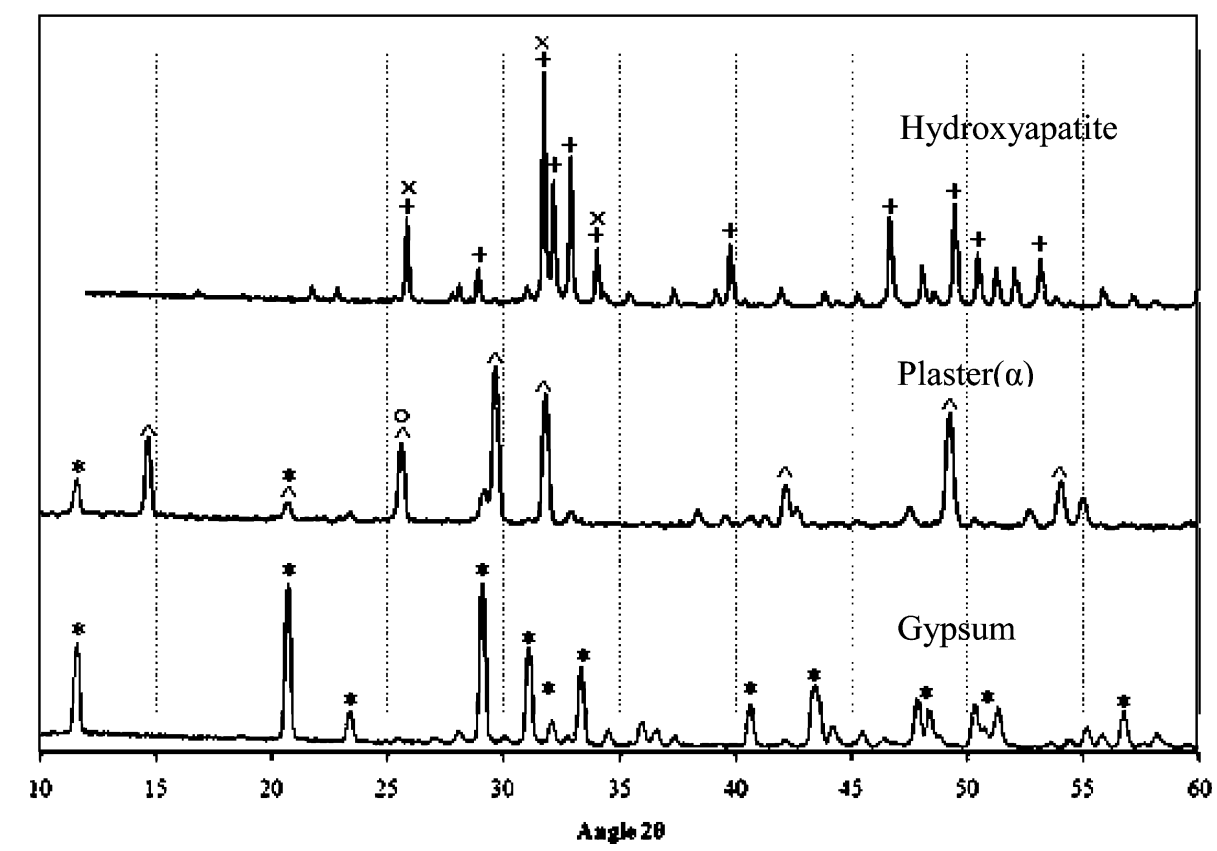

Figure 1. Powder XRD pattern of Ca-HA heated for $10 \mathrm{~h}$ at $1000{ }^{\circ} \mathrm{C}$ [hydroxylapatite $(+)$, hydroxyapatite $(\times)$, plaster $(\wedge)$, gypsum $(*)$, and anhydrite $(O)]$.

times higher than that of gypsum. The specific surface area of $\mathrm{Ca}-\mathrm{HA}_{\mathrm{Powder}}$ indicates the surface reactivity of the particles. The net charge of the materials can be evaluated by referring to the $\mathrm{pH}$ of the aqueous solutions with the metal surface in a neutral electric state and $\mathrm{pH}_{\mathrm{PZC}}$. The plaster and $\mathrm{Ca}-\mathrm{HA}$ particles are positively charged $\left(\mathrm{pH}<\mathrm{pH}_{\mathrm{PZC}}\right)$, and the gypsum particles are negatively charged $\left(\mathrm{pH}>\mathrm{pH}_{\mathrm{PZC}}\right)$.

The classification and identification of materials following the geotechnical designation reveals that plaster and $\mathrm{Ca}-\mathrm{HA}_{\text {Powder }}$ seem to have a silty-sand texture, while gypsum, having a diameter of less than $1 \mathrm{~mm}$, is sandy-silt and $\mathrm{Ca}-\mathrm{HA}_{\mathrm{Gel}}$ is identified as silty (Table 1 ).

XRD analysis of synthesized Ca-HA after heat treatment (calcination at $1000{ }^{\circ} \mathrm{C}$ for $10 \mathrm{~h}$ to crystallize the structure and eliminate calcite residue) showed the existence of a crystalline phase illustrated by hydroxyapatite in large quantities that had synthesized stoichiometrically $\left(\mathrm{Ca}_{10}\left(\mathrm{PO}_{4}\right)_{6} \mathrm{OH}_{2}\right)$. The XRD patterns of gypsum and plaster reveal that there are almost no common peaks. The $\mathrm{P}_{\alpha}$ and $\mathrm{G}$ are characterized by five major peaks at $14.7^{\circ}, 25.7^{\circ}, 29.6^{\circ}, 31.8^{\circ}$, and $49.3^{\circ} 2 \theta$ and 11.6, 20.7, $29.0^{\circ}, 31.1^{\circ}$, and $33.3^{\circ} 2 \theta$, respectively. The presence of an anhydrite peak at $25.7^{\circ} 2 \theta$ appears for the first time after heat treatment (Figure 1). The difference in the structures of both plaster and gypsum is related to the heat treatment, which modifies the crystalline lattice. The study carried out by Mandal et al. demonstrated that heating the gypsum $\left(\mathrm{CaSO}_{4} \cdot 2 \mathrm{H}_{2} \mathrm{O}\right.$; $98 \%$ pure) at 90 and $350{ }^{\circ} \mathrm{C}$ for $10 \mathrm{~h}$ revealed the presence of two kinds of water: loosely and strongly held water molecules. ${ }^{13}$ Consequently, the loss of water molecules modifies the monoclinic structural morphology of gypsum, where the elimination of 1.5 water molecules allows the apparition of hexagonal hemihydrates. Above $200{ }^{\circ} \mathrm{C}$, the symmetry changes to the orthogonal configuration due to the elimination of strongly held water molecules.

\section{RHEOLOGICAL BEHAVIOR}

4.1. Steady Rheological Properties of Ca-HA $\mathrm{Gel}_{\mathrm{Ge}}$. Apatite gel is characterized by a specific texture caused by absorption of water and interaction between fine particles. The identification of the behavior and the structure $\mathrm{Ca}-\mathrm{HA}_{\mathrm{Gel}}$ requires an understanding of the influence of parameters such as material deformation, strength, and stability.

As shown in Figure 2, the shear stress increases with the shear rate when the stress exceeds a threshold value $\tau_{0}(1.425$ $\mathrm{Pa})$, indicating that $\mathrm{Ca}-\mathrm{HA}_{\mathrm{Gel}}$ exhibits a shear thinning or, specifically, a viscoplastic behavior. Studies published by Knowles et al. carried out on a commercial Ca-HA suspension agree with this obtained result. ${ }^{14}$

The viscosity reaches an apparent value of $\eta_{\infty}=0.144 \mathrm{~Pa} \cdot \mathrm{s}$ above $\dot{\gamma}=200 \mathrm{~s}^{-1}$. The critical shear rate corresponding to the $\mathrm{Ca}-\mathrm{HA}$ dispersion is characterized by an extrapolated maximum yield stress $\tau_{0 \mathrm{e}}(2.289 \mathrm{~Pa})$ and a minimum yield stress $\tau_{0}(1.425$ $\mathrm{Pa})$, related to the response of the gel to the deformation. The viscosity of $\mathrm{Ca}-\mathrm{HA}_{\mathrm{Gel}}$ is $0.144 \mathrm{~Pa} \cdot \mathrm{s}$ at a higher shear stress, and above this value, the suspension flows. The increase in the shear stress leads to the disruption of the gel structure, and when the shear stress stops, the suspension tends to recover its original structure (i.e., the flow is reversible).

The viscosity does not only depend on the shear rate, but it is also correlated to the duration of the applied stress. The internal structure of $\mathrm{Ca}-\mathrm{HA}_{\mathrm{Gel}}$ undergoes an initial homogenization at low shear rate values corresponding to low levels of plasticity. The constraint force is too small to disorganize the structure; it requires an increase in the magnitude of the applied force for the flow to occur. Beyond the shear stress threshold, with an increasing shear rate, the flow is enhanced by the gradual dispersion of particles, promoting the separation effect, which causes a decrease in the viscosity. The viscosity (apparent viscosity) value stabilizes at high shear rates. Once the apparent viscosity is reached, there is no further modification observed for the structure of $\mathrm{Ca}-\mathrm{HA}_{\mathrm{Gel}}$. 

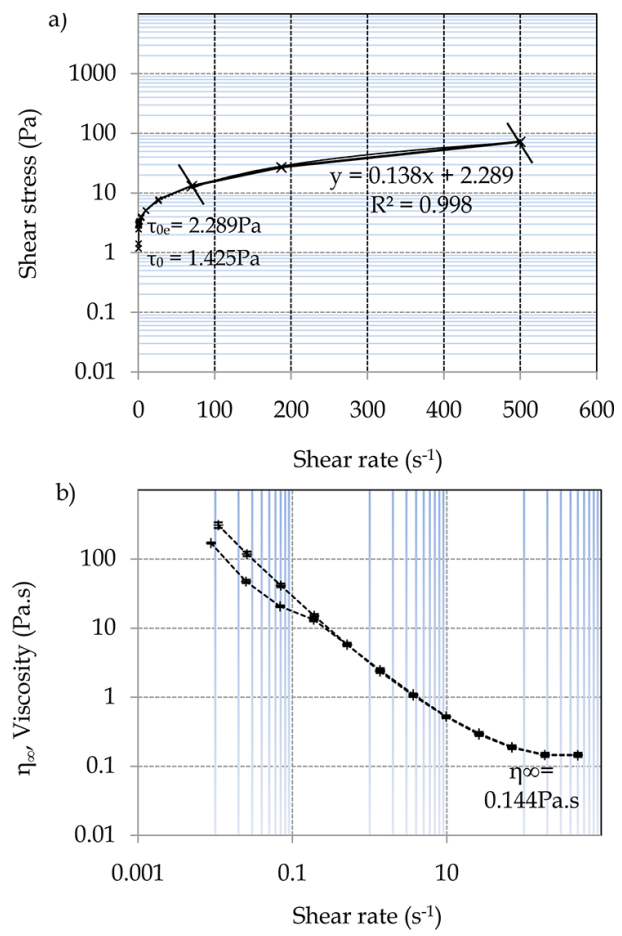

Figure 2. Rheological behavior and viscosity of $\mathrm{Ca}-\mathrm{HA}_{\mathrm{Gel}}$ after $48 \mathrm{~h}$ of synthesis: (a) $\tau=f(\dot{\gamma})$; (b) $\log (\tau)=f(\dot{\gamma})[-\times-$, shear stress $(\mathrm{Pa})$; +- , viscosity $(\mathrm{Pa} \cdot \mathrm{s})]$.

4.2. Dynamic Rheological Properties of Ca-HA. To explain the viscoelastic behavior observed for $\mathrm{Ca}-\mathrm{HA}_{\mathrm{Gel}}$, dynamic oscillatory tests were carried out to investigate the internal structure and response of the gel during $\mathrm{Ca}-\mathrm{HA}$ synthesis. The dynamic rheological (oscillatory) test aims to determine the storage $\left(G^{\prime}\right)$ and loss $\left(G^{\prime \prime}\right)$ moduli. Figure 3 represents the results of the frequency-sweep response of a Ca-HA suspension after 12, 24, 48, and $72 \mathrm{~h}$ of synthesis.
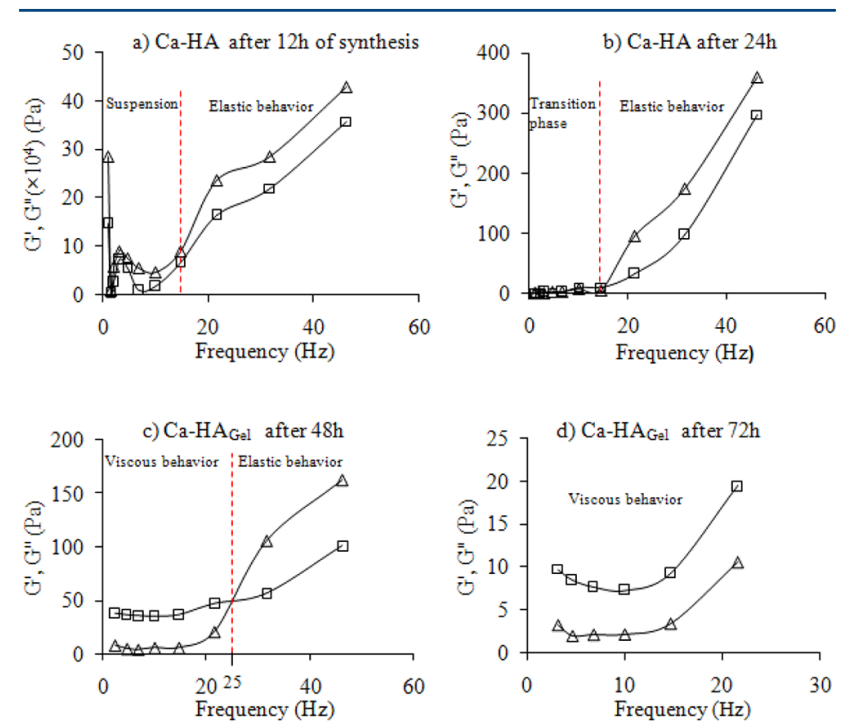

Figure 3. Frequency-sweep curves of $\mathrm{Ca}-\mathrm{HA}$ as a function of the synthesis time $\left(-\Delta-\right.$, storage modulus $G^{\prime},-\square-$, loss modulus $\left.G^{\prime \prime}\right)$. The description of the behavior of $\mathrm{Ca}-\mathrm{HA}_{\mathrm{Gel}}$ is based on two conditions: if $G^{\prime}>G^{\prime \prime}$, the behavior is elastic; if $G^{\prime}<G^{\prime \prime}$, the behavior is viscous.
During synthesis, the storage and loss moduli $\left(G^{\prime}\right.$ and $\left.G^{\prime \prime}\right)$ rose with an increase in the frequency and their values decreased with the aging of the gel.

At low frequencies, the $12 \mathrm{~h}$ age dispersion (Figure 3a) seems to have a heterogeneous structure at the beginning of the periodic oscillation application. It is observed that $G^{\prime}$ is greater than $G^{\prime \prime}$, which corresponds to an elastic behavior. Therefore, when the frequency is increased, the modulus values increase strongly because of the dispersed state of the particles.

For a $24 \mathrm{~h}$ age dispersion (Figure $3 \mathrm{~b}$ ), the values of the storage and loss moduli are almost zero below $15 \mathrm{~Hz}$. The strain response at constant stress after $24 \mathrm{~h}$ of synthesis is delayed compared to the $12 \mathrm{~h}$ age dispersion measurement. This change in behavior, identified at low frequencies, is due to the evolution of the reaction. This response is related to precipitation of the $\mathrm{Ca}-\mathrm{HA}$ suspension occurring when the $\mathrm{pH}$ value buffers around 8 , leading to the formation of a colloidal suspension. The behavior remains elastic at high-frequency values.

After $48 \mathrm{~h}$ of synthesis (Figure 3c), we observe a complete change in behavior at low frequencies. For frequencies below $25 \mathrm{~Hz}, G^{\prime}$ and $G^{\prime \prime}$ increase exponentially at low stress. Below 25 $\mathrm{Hz}, G^{\prime \prime}$ is greater than $G^{\prime}$, indicating viscous behavior. This simply means that the suspension follows a constant structural deformation where the stress is proportional to the strain rate. When the frequency reaches values higher than $25 \mathrm{~Hz}, \mathrm{G}^{\prime \prime}$ becomes smaller than $G^{\prime}$, indicating an elastic behavior: the stress is proportional to the deformation. However, the viscosity increases progressively, indicating the agglomeration of colloids and the formation of gel-paste calcium phosphate. This result is important because it shows the transition between a suspension and pasty behavior. As demonstrated by Knowles et al. ${ }^{14}$ and Bao et al., ${ }^{15}$ the mutual approach of particles in solution is correlated to the positive charge of the Ca-HA surface. The behavioral changes show the formation of gel particles or gel-paste structures after 2 days of reaction, exhibiting a viscoelastic behavior. The dynamic rheological property study carried out by Liu et al. ${ }^{16}$ on a calcium phosphate cement slurry (a composite of equimolar tetracalcium and dicalcium phosphate anhydrous) under the conditions of a 2.0 powder/liquid ratio and a $1 \%$ strain showed that, at the range of low strain and low frequency, the slurry changed its behavior with frequency increases. The slurry began to flow and presented a shear-thinning behavior.

For the $72 \mathrm{~h}$ age dispersion (Figure $3 \mathrm{~d}$ ), the loss modulus values are higher than the storage modulus values, thus revealing a viscous behavior. Nevertheless, when the frequency increases and the strain exceeds the yield strain, the viscosity decreases. The decrease in the $G^{\prime}$ and $G^{\prime \prime}$ values is due to gel aging after $48 \mathrm{~h}$ of synthesis, which causes deformation of the gel structure. The disruption of extractible water molecules caused by bonds between particles leads to flow and demonstrates that $\mathrm{Ca}-\mathrm{HA}_{\mathrm{Gel}}$ exhibits a shear-thinning behavior.

4.3. Rheological Behavior of Binary Blends. The viscosity of the binary matrix was measured and plotted versus the concentration of added powder, as illustrated in Figures 4 and $5 . \mathrm{W} / \mathrm{G}$ and $\mathrm{W} / \mathrm{P}$ blends exhibit shear-thinning behavior. Figure 4 shows that the viscosity of W/G blends decreases with decreasing gypsum concentration until an almost constant apparent viscosity for $\mathrm{W} / \mathrm{G}$ ratios above 0.6 was achieved. The viscosity plateau reveals no influence of water on the hydrated gypsum particles. Hydrated gypsum particles present similar double-electric layers of a common charge (negatively 

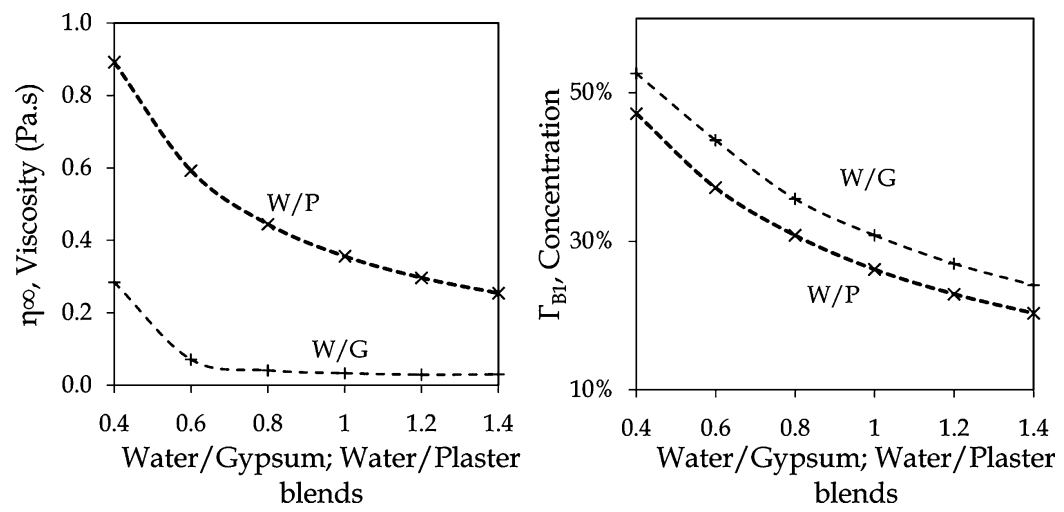

Figure 4. Viscosities of $\mathrm{W} / \mathrm{G}$ and $\mathrm{W} / \mathrm{P}$ blends at different mass ratios.
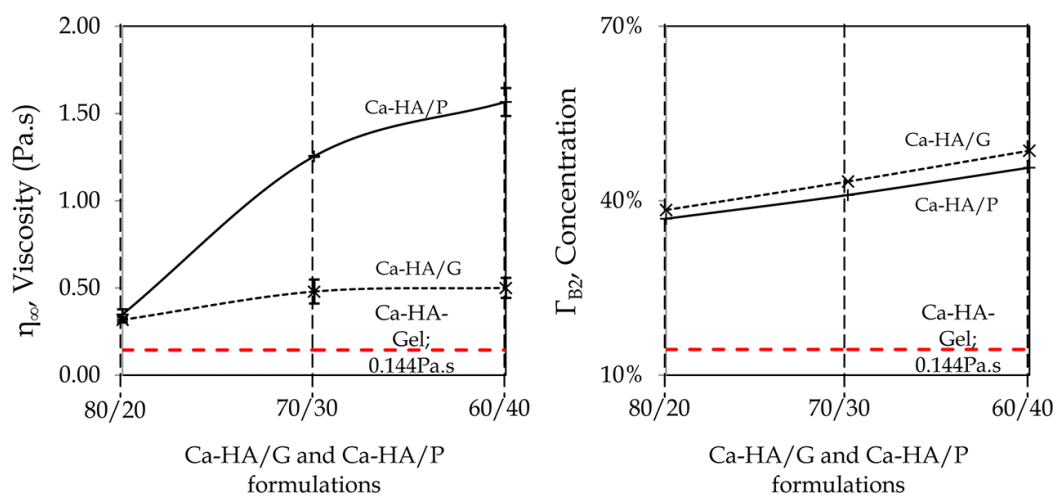

Figure 5. Viscosities of Ca-HA/G and Ca-HA/P formulations.

charged), which generates electrostatic repulsion between particle surfaces (due to the overlap of the electrical double-layer theory). Gypsum particles are mainly positively charged and are covered by a layer of positive average charge. This positivecharge layer stabilizes the dispersion through particle repulsion, avoiding particle aggregation. At rest, particles tend to precipitate. If a stress is applied, the suspension is dispersed, leading to a decrease in the viscosity. The gypsum concentration controls the dispersed state; the repulsive forces tend to stabilize the suspension because the particles are negatively charged. The apparent viscosity is obtained at a high shear rate, where gravity forces are negligible. It can be seen that, above a $0.6 \mathrm{~W} / \mathrm{G}$ ratio, the interparticle distance is large enough to make the apparent viscosity independent of the gypsum content.

With regards to the plaster blends (W/P), the viscosity decreases with decreasing plaster concentration. The hydration of hemihydrate particles, requiring 1.5 water molecules, leads to crystallization. In general, the contact of plaster particles with water triggers dissolution, which induces the saturation or supersaturation of the solution in $\mathrm{Ca}^{2+}$ and $\mathrm{SO}_{4}{ }^{2-}$, leading to the formation of gypsum nuclei. ${ }^{17}$ Consequently, the hydration control scenario is correlated with the nucleation and crystalgrowth mechanism. $^{18,19}$

The high specific surface area of plaster particles plays a major role in the multiplication of intergranular links. Interaction between plaster particles occurs by electrostatic forces (i.e., the spread of ions in an extended diffuse layer) and attractive forces (van der Waals) responsible for adhesion. Furthermore, adhesion is described as the formation of two $\mathrm{Ca}^{2+} / \mathrm{SO}_{4}{ }^{2-}$ layers bound together by ionic interaction, constructing a growth slice. ${ }^{17}$ The predominance of reactive sites on the grains attracts cations, which form a rigid network that surrounds the layer of adsorbed water molecules. It is also known that the attraction of plaster particles requires cohesion between atoms to form the contiguous flakes. The development of this structure (agglomerated structure or plaster paste) depends on the amount of hydration water. According to the stochiometry, the $\alpha$-hemihydrates require a $\mathrm{W} / \mathrm{P}$ ratio higher than 0.186 to be transformed into gypsum. To improve the consistency of the blends, the hydration rate was chosen from a range of $0.4-1.4$. In the dynamical study in the linear viscoelastic domain published by Finot et al., the time-sweep test at $0.015 \%\left(\omega=10 \mathrm{rad} \cdot \mathrm{s}^{-1}\right)$, carried out on $\mathrm{W} / \mathrm{P}=0.7$, indicates that the rise in the storage modulus reflects the hydration and setting processes. This reveals an increase in the level of crystallized gypsum. ${ }^{20}$ Obviously, the viscosity decreases steadily with an increasing amount of water, and the application of shear stress destroys the links between particles, facilitating decoagulation of the structure and leading to flow.

Plaster hydrates during viscosity measurement under stress. The plaster viscosity value depends on the volume fraction of the solids (solid concentration $\Gamma_{\mathrm{B} 1}$ ), particle size, and water excess (free of water after full plaster hydration). At a high shear rate, it is possible to measure the apparent viscosity of the dispersion of agglomerated hydrated particles. The apparent viscosities of $\mathrm{W} / \mathrm{G}$ blends are lower than those of $\mathrm{W} / \mathrm{P}$ blends. Because plaster hydration held the measurement long, the difference observed in the apparent viscosity between $W / G$ and $\mathrm{W} / \mathrm{P}$ cannot be solely attributed to hydration. The difference observed in a specific surface area may provide an explanation. 
Figure 5 shows that the viscosity increases when the solid concentration $\left(\Gamma_{\mathrm{B} 2}\right)$ increases, with the latter being calculated relative to the water (by wt \%) present in $\mathrm{Ca}-\mathrm{HA}_{\mathrm{Gel}}$. It should be noted that the formulations having $\mathrm{Ca}-\mathrm{HA}_{\mathrm{Gel}} / \mathrm{G}$ or $\mathrm{Ca}-$ $\mathrm{HA}_{\mathrm{Gel}} / \mathrm{P}$ ratios higher than 1.5 are solids and their rheological properties were not characterized. The water content in Ca-HA is more than sufficient to hydrate calcium sulfate hemihydrate particles. In this case, an almost solid paste is formed. Replacing $20 \%$ of $\mathrm{Ca}-\mathrm{HA}_{\mathrm{Gel}}$ by gypsum or plaster produced little influence on the viscosity, indicating that for this blend there is little influence of calcium sulfate on the rheological properties of Ca$\mathrm{HA}_{\mathrm{Gel}}$. With regards to the already hydrated gypsum particles, increasing the gypsum concentration of the blend up to $40 \%$ produced a slight increase in the viscosity. Blends containing more than $40 \%$ of gypsum are almost solids. The addition of plaster to Ca-HA requires a high stress to cause the flow. Plaster particles in contact with Ca-HA water cause plaster hydration, creating strong bonds that encompass the Ca-HA particles and make the flow of the blend difficult. Hydrated plaster strongly increases the viscosity of Ca-HA $\mathrm{Hel}_{\mathrm{Gel}}$ by its own weight. Figure 6 shows the thixotropic behavior of binary

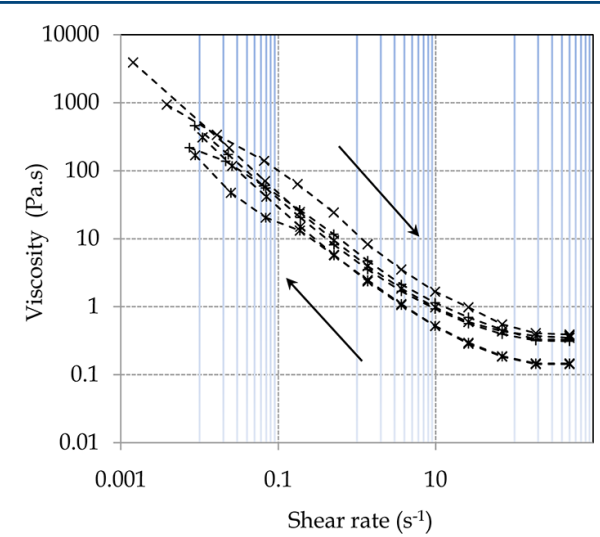

Figure 6. Example of a thixotropic hysteresis loop of composites $80 \%$ Ca-HA/20\% G and 80\% Ca-HA/20\% P [-*, Ca-HA ${ }_{\text {Gel }}\left(\eta_{\infty}=0.144\right.$ $\mathrm{Pa} \cdot \mathrm{s}) ;-\mathrm{X}-, 80 \% \mathrm{Ca}-\mathrm{HA}_{\mathrm{Gel}} / 20 \% \mathrm{P}\left(\Gamma=0.369 ; \eta_{\infty}=0.348 \mathrm{~Pa} \cdot \mathrm{s}\right) ;-+-$, $\left.80 \% \mathrm{Ca}-\mathrm{HA}_{\mathrm{Gel}} / 20 \% \mathrm{G}\left(\Gamma=0.384 ; \eta_{\infty}=0.318 \mathrm{~Pa} \cdot \mathrm{s}\right)\right]$.

blends containing a mass ratio blend of $80 \%$ of Ca-HA and $20 \%$ of plaster and a mass ratio of $80 \%$ of $\mathrm{Ca}-\mathrm{HA}$ and $20 \%$ of gypsum, indicating that the blends recover their initial structure. In this case, viscosity values increase slightly compared to the viscosity of $\mathrm{Ca}-\mathrm{HA}_{\mathrm{Gel}}$ while keeping their flow characteristics.

4.4. Interaction between Particles. The interpretation of interactions between these compounds seems to be complex. The $\zeta$ potential was considered as a means to understanding the interactions, based on the net charge of the particles, and hence describing the suspension structure. The $\zeta$ potential indicates the repulsion forces between particles promoting the dispersion stability. Figure 7 shows that the Ca-HA particles are characterized by a negative $\zeta$ potential, indicating that the particles are negatively charged $(\approx-20 \mathrm{mV})^{14}$ and the gypsum particles are positively charged $(\approx 20 \mathrm{mV}){ }^{21}$ The Ca-HA $\zeta$ potential value indicates the instability of the gelled particles. Adding gypsum to Ca-HA leads to charge modification. The presence of repulsive forces is correlated to the high value of the $\zeta$ potential predicting the stability. These results support the assumption of sulfate attraction on the Ca-HA surface, indicating dispersion of the particles. However, sulfate adsorption changed the charge distribution of Ca-HA,

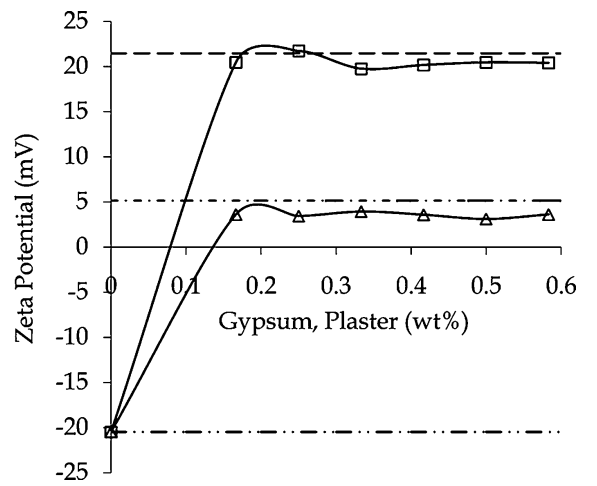

Figure 7. $\zeta$ potential of $\mathrm{Ca}-\mathrm{HA} / \mathrm{G}$ and $\mathrm{Ca}-\mathrm{HA} / \mathrm{P}$ formulations without added water $[--, \zeta$ potential of gypsum $(\approx 20 \mathrm{mV}) ;-\cdot-, \zeta$ potential of plaster $(\approx 5 \mathrm{mV}) ;-\cdot--, \zeta$ potential of Ca-HA $(\approx-20 \mathrm{mV}) ;-\square-$, $\zeta$ potential of Ca-HA/G formulations; $-\Delta-, \zeta$ potential of $\mathrm{Ca}-\mathrm{HA} / \mathrm{P}$ formulations].

generating the change from negative to positive charge. The adsorbed amount of anionic sulfate on the Ca-HA particles is equal to the Ca-HA electrical charge sites, and the coating of gypsum sulfate $\mathrm{Ca}-\mathrm{HA}$ particles is the main reason for modification of the $\zeta$ potential. The surfaces of the plaster particles are characterized by a positive charge, and the formation of a plaster solid body is explained by cohesion between particles and illustrated by a low $\zeta$-potential value.

Figure 7 represents the $\zeta$ potential of formulations containing $\mathrm{Ca}-\mathrm{HA}$ and different proportions of the $\mathrm{W} / \mathrm{P}$ ratio. With an increase in the amount of plaster, the $\zeta$ potential remains constant (with values similar to those of the plaster at the beginning of the hydration process) and the surface charge of $\mathrm{Ca}-\mathrm{HA}$ changes. The nucleation process of hemihydrated particles starts by the formation of $\mathrm{Ca}^{2+} / \mathrm{SO}_{4}{ }^{2-}$-bound double layers, and the concentration of sulfate decreases, indicating that it is consumed during hydration. However, fixation of the remaining sulfate in solution on the Ca-HA surface leads to a change in the charge.

\section{CONCLUSION}

The rheological test carried out reveals shear thinning and the thixotropic behavior of $\mathrm{Ca}-\mathrm{HA}_{\mathrm{Gel}}$ for formulations considered. The internal structure of $\mathrm{Ca}-\mathrm{HA}_{\mathrm{Gel}}$ exhibits viscoelastic behavior after $48 \mathrm{~h}$ of synthesis.

The positively charged gypsum particles cause repulsion of the particles (repulsive forces), and the viscosity of the W/G $(0.2-1.4)$ blends remains constant. Plaster is characterized by attractive forces, and the particles are positively charged. The hydration of plaster leads to cohesion between particles, which explains the increase in the viscosity of the $\mathrm{W} / \mathrm{P}$ blends compared to the $\mathrm{W} / \mathrm{G}$ blends. The $\zeta$ potential of $\mathrm{Ca}-\mathrm{HA}$ is negative, and dissolution of the calcium sulfate particles saturates the solution in sulfate ions $\left(\mathrm{SO}_{4}{ }^{2-}\right)$; the charge of the particles becomes positive because of fixation of $\mathrm{SO}_{4}{ }^{2-}$ on the Ca-HA surface. The adsorption of sulfate on the Ca-HA particle surfaces influences the structures of the formulations and explains why the viscosity is independent of the $\mathrm{Ca}-\mathrm{HA}_{\mathrm{Gel}}$ content. Plaster hydration plays a major role in the $\mathrm{Ca}-\mathrm{HA}_{\mathrm{Gel}}$ stabilization structure, and gypsum particles undoubtedly enhance the hydraulic performance. Modification in the $\zeta$ potential can affect the retention capacity, reactivity, and mechanical resistance. These aspects will be the subject of a later study. 
This study has led to the understanding of the rheological and physicochemical behavior on water/calcium sulfates and hydroxyapatite/calcium sulfate blends. These results will be useful in the formulation of a permeable reactive barrier.

\section{AUTHOR INFORMATION}

\section{Corresponding Author}

*Tel: +(00)33563493241. E-mail: Mohamed.Raii@mines-albi. fr.

\section{Notes}

The authors declare no competing financial interest.

\section{ACKNOWLEDGMENTS}

The authors are thankful to PRAYON Belgium for providing gypsum and plaster and their interest in the present study.

\section{REFERENCES}

(1) Chen, X.; Wright, J. V.; Conca, J. L.; Peurrung, L. M. Evaluation of heavy metal remediation using mineral apatite. Water, Air, and Soil Pollution 98; Kluwer Academic Publishers: Dordrecht, The Netherlands, 1997; pp 57-78.

(2) Nzihou, A.; Sharrock, P. Calcium phosphate stabilization of fly ash with chloride extraction. Waste Manage. 2002, 22 (2), 235-239.

(3) Baillez, S.; Nzihou, A.; Bernache-Assolant, D.; Champion, E.; Sharrock, P. Removal of aqueous lead ions by hydroxyapatites: Equilibria and kinetic processes. J. Hazard. Mater. 2007, A139, 443446.

(4) Moore, R. C. Stabilization and Solidification of Hazardours. In Radioactive and Mixed Wastes; Roger, D. S., Shi, C., Eds.; 2005; CRC Press, pp 98-112; available on http://www.books-google.fr.

(5) Conca, J.; Wright, J. An Apatite II permeable reactive barrier to remediate groundwater containing $\mathrm{Zn}, \mathrm{Pb}$ and $\mathrm{Cd}$. Appl. Geochem. 2006, 21 (12), 2188-2200.

(6) Tayibi, H.; Choura, M.; Lopez, F. A.; Alguacil, F. J.; LopezDelgado, A. Environmental impact and management of phosphogypsum. J. Environ. Manage. 2009, 90, 2377-2386.

(7) Degirmenci, N.; Okucu, A.; Turabi, A. Application of phosphogypsum in soil stabilization. Building Environ. 2007, 42, 3393-3398.

(8) Kuryatnyk, T.; Angulski da luz, C.; Ambroise, J.; Pera, J. Valorization of phosphogypsum as hydraulic binder. J. Hazard. Mater. 2008, 160, 681-687.

(9) Iribarne, A. P.; Iribarne, J. V.; Anthony, E. J. Reactivity of calcium sulfate from FBC systems. Fuel 1997, 76 (4), 321-327.

(10) Auvray, C.; Homand, F.; Hoxha, D. The influence of relative humidity on the rate of convergence in an underground gypsum mine. Int. J. Rock Mech. Mining Sci. 2008, 45 (8), 1454-1468.

(11) Finot, E.; Lesniewska, E.; Mutin, J.-.C; Goudonnet, J.-P. Reactivity of gypsum faces according to the relative humidity by scanning force microscopy. Surf. Sci. 1997, 384, 212-217.

(12) Fan, C.; Teng, H. Surface behavior of gypsum during dissolution. Chem. Geol. 2007, 245 (3-4), 242-253.

(13) Mandal, P. K.; Mandal, T. K. Anion water in gypsum $\left(\mathrm{CaSO}_{4} \cdot 2 \mathrm{H}_{2} \mathrm{O}\right)$ and hemihydrates $\left(\mathrm{CaSO}_{4} \cdot{ }^{1} /{ }_{2} \mathrm{H}_{2} \mathrm{O}\right)$. Cem. Concr. Res. 2002, 32, 313-316.

(14) Knowles, J. C.; Callcut, S.; Georgiou, G. Characterisation of the rheological properties and zeta potential of a range of hydroxyapatite powders. Biomaterials 2000, 21 (13), 1387-1392 . Retrieved from http://www.ncbi.nlm.nih.gov/pubmed/10850933.

(15) Bao, Y.; Senos, A. M. R.; Almeida, M.; Gauckler, L. J. Rheological behavior of aqueous suspensions of hydroxyapatite (HAP). J. Mater. Sci.: Mater. Med. 2002, 13 (7), 639-43 . Retrieved from http://www.ncbi.nlm.nih.gov/pubmed/15348572.

(16) Liu, C.; Shao, H.; Chen, F.; Zhen, H. Rheological properties of concentrated aqueous injectable calcium phosphate cement slurry. Biomaterials 2006, 27, 5003-5013.
(17) Singh, N. B.; Middendorf, B. Calcium sulphate hemihydrate hydration leading to gypsum crystallization. Prog. Cryst. Growth Charact. Mater. 2007, 53, 57-77.

(18) Bosbach, D.; Junta-Rosso, J. L.; Becker, U.; Hochella, M. F., Jr. Gypsum growth in the presence of background electrolytes studied by Scanning Force Microscopy. Geochim. Cosmochim. Acta 1996, 60 (No. 17), 3295-3304.

(19) Sievert, T.; Wolter, A.; Singh, N. B. Hydration of anhydrite of gypsum $\left(\mathrm{CaSO}_{4}\right.$.II) in a ball mill. Cem. Concr. Res. 2005, 35, 623-630.

(20) Finot, E.; Lesniewska, E.; Mutin, J.-C.; Goudonnet, J.-P.; Mutin, J.-C.; Domenech, M.; Ait Kadi, A. Correlation surface forces with surface reactivity of gypsum crystals by atomic force microscopy. Comparison with rheological properties of plaster. Solid State Ionics 2001, 141-142, 39-46.

(21) Peng, J.; Qu, J.; Zhang, J.; Chen, M.; Wan, T. Adsorption characteristics of water-reducton agents on gypsum surface and its effects on the rheology of gypsum plaster. Cem. Concr. Res. 2005, 35, $527-531$. 